J. Nat. Hist. Mus. Vol. 30, 2016-18 287-293

\title{
Prevalence of gastrointestinal parasites of pigeons (Columba sp. Linnaeus, 1758) in three temples of Pokhara valley, Nepal
}

\author{
Amrit Gurung $^{1}$ and Janak Raj Subedi ${ }^{1} \bowtie$ \\ ${ }^{1}$ Central Department of Zoology, Tribhuvan University, Kirtipur, Kathmandu, Nepal \\ janzoology@gmail.com
}

\begin{abstract}
The present study was conducted to determine the general prevalence, identification, compare area-wise as well as infection-wise prevalence and find out activities on health care of pigeon (Columba sp.) in three temples viz. Bhadrakali temple, Bindhyabasini temple and Tal Barahi temple of Pokhara valley. lodine wet mount and different concentration technique (floatation and sedimentation) were used for faecal qualitative tests whereas verbally administered questionnaires for interview and Microsoft Excel and "R" software packages were used in analyzing data. Out of 120 faecal samples collected by opportunistic random faecal sampling method examined, general prevalence rate of parasitic infection was $69.16 \%$. Total of seven gastrointestinal parasites that includes one subclass of protozoan: Coccidia $(19.16 \%)$ and six genera of helminths: Capillaria sp. (31.67\%), Ascaridia sp. (21.66\%), Echinostoma sp. (7.50\%), Syangamus sp. (5.83\%), Hymenolepis sp. (3.33\%) and Hetarakis sp. (2.50\%) were identified and reported first time in Nepal. The prevalence rates $(55 \%)$ of helminths were higher than protozoan parasites (19.16\%). The higher prevalence of gastrointestinal parasites was in Bhadrakali temple with $77.50 \%$ followed by Tal Barahi temple $(72.50 \%)$ and lowest in Bindhyabasini temple (57.50\%). Statistically, the difference in prevalence of gastrointestinal parasitic infection among study area was found to be insignificant whereas the difference in prevalence of single infection (43.83\%) and mixed infections (25.83\%) were also insignificant. No any activities on health care of pigeon regarding the gastrointestinal parasites were found. The study indicates that pigeons in three temples of Pokhara valley were highly susceptible to gastrointestinal parasites.
\end{abstract}

Keywords: Ascaridia, Capillaria, faecal, prevalence, susceptible

\section{INTRODUCTION}

Pigeons are ubiquitous birds and found virtually in every town and city around the globe (Marques et al., 2007) and related to human since ancient time (B.C. 3000-5000). They live side by side with human as a source of food, hobby, experimental purpose, cultural and religious symbols (Sari et al., 2008). About 100 different breeds and varieties are described in more or less detail (Levi, 1969). In Nepal, six species of Columba are recorded: (Columba livia Gmelin, 1789), (Columba rupestris Pallas, 1811), (Columba leuconata Vigors, 1831), (Columba palumbus Linnaeus, 1758), (Columba hodgsonii Vigors, 1832) and (Columba pulchricollis Blyth, 1846) (BCN \& DNPWC, 2016). They are primarily grain and seed eaters 
and subsist on spilled or improperly stored grain and also feed on garbage, livestock manure, insects, or other food materials provided for them intentionally or unintentionally by people (Williams \& Corrigan, 1994).

Parasites may be responsible for a number of serious health problems among pigeons either directly or indirectly. Avian parasites commonly seen include protozoa (one-celled animals), helminths (worms) and arthropods (insects and mites). The effects vary from benign to acute death (Ritchie et al., 1997). Free-range scavenging birds are in direct contact with parasite vectors, soil and faeces. On the other hand, lack of hygiene, direct contact with humans, captivity conditions and the physical environment (rainfall, humidity and ambient temperature) provides optimum conditions to maintain parasites populations (Alves et al., 2008). Among the reviewed literature, Ascardia sp., Capillaria sp., Raillietina sp., and coccidian oocysts were commonly found gastrointestinal parasites in pigeons. In spite of its susceptibility against gastrointestinal parasites, the study on prevalence in Nepal is still untouched. Hence this study is aimed to determine general prevalence of gastrointestinal parasites, identify them up to genus level, to compare area-wise and infection wise prevalence and find out health care of pigeon regarding the gastrointestinal parasites.

\section{MATERIALS AND METHODS}

\section{Study area}

Pokhara is second largest city of Nepal. It is headquarter of both the western development region and the Kaski district. The pocket areas of present study are Bhadrakali temple, Bindhyabasini temple and Tal Barahi temple.
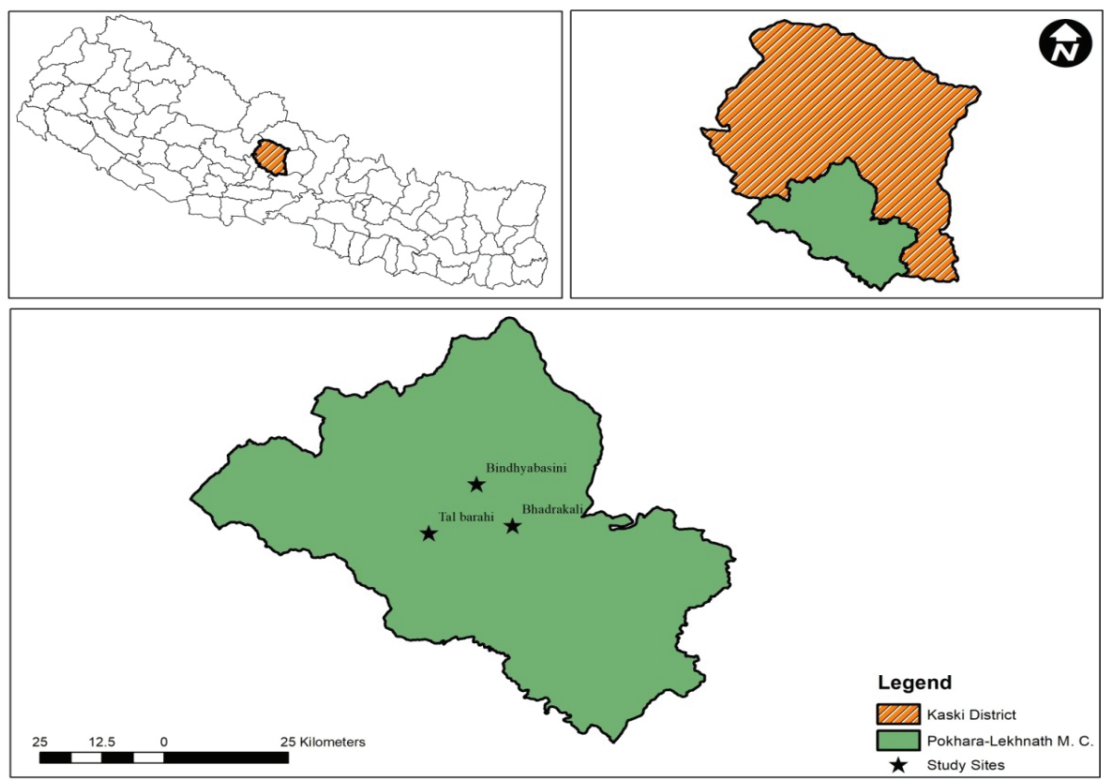

FIG. 1. Map of Pokhara-Lekhnath showing study sites. 


\section{Collection of samples}

Total of 120 fresh faecal samples of Columba sp. were collected by opportunistic random sampling method in early hours of morning on 16 to 19 March, 2016. It took each morning to collect 40 samples from each site (fig. 1). The samples were preserved in $2.5 \%$ potassium dichromate. Verbally administered questionnaire survey was conducted with the key informants of three temples and District Livestock Service Office, Kaski district regarding the activity on parasites of pigeon. The samples were examined by iodine wet method and different concentration techniques (floatation and sedimentation). Eggs and cysts size were measured by using micrometry and identified by morphological basis. The recorded data were coded and entered into Microsoft Excel 2007. Statistical analysis was performed using "R", version 3.3.1 software packages.

\section{Results and discussion}

Out of 120 faecal samples examined, 83 samples were positive for one or more specific gastrointestinal parasites, showing $69.16 \%$ prevalence of parasitic infection. One sub-class of protozoa: Coccidia and six genera of helminths: Capillaria sp. $38(31.67 \%)$ showed highest prevalence, Ascaridia sp. 26 (21.66\%), Echinostoma sp. 9 (7.50\%), Syangamus sp. 7 (5.83\%), Hymenolepis sp. 4 (3.33\%) and Hetarakis sp. 3 (2.50\%) have been identified which are all reported first time from pigeons in Nepal (fig. 2).

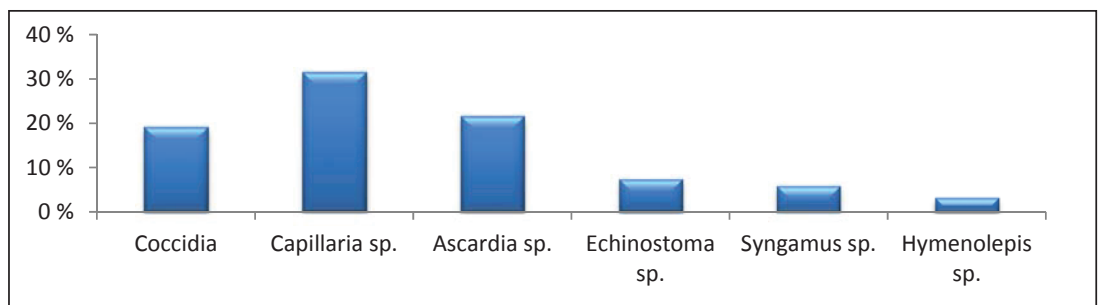

FIG. 2. Prevalence of specific gastrointestinal parasites.

As shown in fig. 3, out of total samples, 66 (55\%) were positive with helminths whereas $23(19.16 \%)$ were positive with protozoan parasites. Among the study area, the highest prevalence of gastrointestinal parasites was in Bhadrakali temple $31(77.50 \%)$ followed by Tal Barahi temple 29 (72.50\%) and the lowest was in Bindhyabasini temple $23(57.50 \%)$. Statistically, the difference in prevalence of gastrointestinal parasitic infection among study area was found to be insignificant $\left(X^{2}=0.76328, P>0.05\right)$.

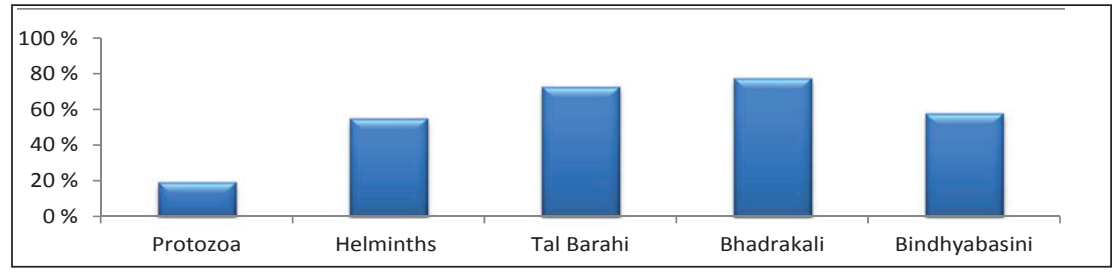

FIG. 3. Prevalence of protozoan and helminth parasites and their infections among study area. 
The higher prevalence was of single infection 52 (43.33\%) than mixed infections 31 (25.83\%) in total sample. Statistically, the differences in the prevalence of single and mixed infections were found to be insignificant $\left(X^{2}=3.4728, P>0.05\right)$. No any activity on health care of pigeon regarding the gastrointestinal parasites was found from key informants of three temples and District Livestock Service Office, Kaski.

The general prevalence rate $(69.16 \%)$ of gastrointestinal parasites in the present study showed similar prevalence rates $74.14 \%, 72 \%$ and $72.70 \%$ obtained by the previous studies (Marques et al., 2007; Sivajothi \& Sudhakara, 2015; Ghosh et al., 2014) respectively. It was lower as compared to $100 \%$ prevalence rate of others finding (Al-Barwari \& Saeed, 2012) whereas higher than $53.57 \%, 46.70 \%$ and $46.12 \%$ obtained by previous studies (Patel et al., 2000; Sari et al., 2008; Opara et al., 2012) respectively. All rates of prevalence indicate health of pigeon is in risk.

The prevalence rate $(19.16 \%)$ of coccidian parasites in present study showed similarity with $17.92 \%, 11 \%$ and $7.07 \%$ of previous studies (Patel et al., 2000; Ghosh et al., 2014; Bahrami et al., 2013) respectively. This rate was lower as compared to $49.20 \%, 46.27 \%, 46.20 \%, 43.15 \%$ and $31 \%$ of previous studies (Natala et al., 2009; Nagwa et al., 2013; Sari et al., 2008; Radfar et al., 2011; Sivajothi \& Sudhakara, 2015) respectively. Coccidiosis infected birds generally exhibit loss of appetite, weakness, ruffled feathers, bloody diarrhea and can only be diagnosed by post-mortem examination (Dingle \& Shanawany, 1999). The difference in prevalence rates of coccidian might be due to difference in practice of management area, hygiene of pens, flock structure, samples collected and laboratory techniques. In the temperate regions, the eggs of Eimeria cannot embryonate and develop to infectivity during the winter season of temperature below $10-15^{\circ} \mathrm{C}$ (Permin \& Jorgen, 1998) might also cause low prevalence of Coccidia.

The prevalence of helminths was higher than protozoan parasites in present study. Higher prevalence of helminths than protozoan parasites was also reported previously (Patel et al., 2000). The prevalence rate $(55.50 \%)$ of helminths was similar to prevalence rates of $56.10 \%$, $48.30 \%$ and $42.15 \%$ obtained by previous studies (Adang et al., 2009; Adang et al., 2008; Radfar et al., 2011) respectively. The high prevalence of helminth infections recorded in this study could be an indication of a high incidence of the infective stages and intermediate hosts of the parasites in places where these pigeons are reared. The intermediate hosts of these parasites; beetles, pill bugs, ants, earthworms and snails which form part of the diet of Pigeons (Adang, 1999).

The presence of dense forest, pond, canal and human habitation might be the cause of high prevalence rate of gastrointestinal parasites in Bhadrakali temple than other pocket area. Statistically, difference in prevalence of gastrointestinal parasitic infection among study area was found to be insignificant $\left(X^{2}=0.76328, P>0.05\right)$. It might be because of similar climate, food resources and environment.

There was no significant differences $\left(X^{2}=3.4728, P>0.05\right)$ in the prevalence of single and mixed infections in present study. The higher prevalence of single infection $(43.33 \%)$ was seen than mixed infections (25.83\%) which was also seen in the previous studies (Adang et al., 2008; Adang et al., 2009; Bahrami et al., 2013). The high prevalence of single infections 
in the pigeons may suggest a form of competition that kept the other species away (Kennedy, 1975). It may be also because of crowding of effect of pigeons in pens and nest too.

No any activities on health care of pigeon such as routinely faecal examination, deworming and other medication regar ding the gastrointestinal parasites was found during verbally administered questionnaires taken with the priest of Bindhyabasini temple, worker of Tal Barahi temple, management chief of Bhadrakali temple and from District Livestock Service Office, Kaski.

The study indicates that pigeons in three temples of Pokhara valley were highly susceptible to gastrointestinal parasites. Therefore sustainable ways for controlling the parasitic infection and further studies need to be designed for the health and conservation of pigeons.

\section{ACKNOWLEDGEMENTS}

We are thankful to our respected Head of Department Prof. Dr. Ranjana Gupta, Central Department of Zoology, Tribhuvan University, Kirtipur. We would also acknowledge to all the teachers, friends and staffs of Central Department of Zoology for their continuous aspiration and motivation.

\section{REFERENCES}

ADANG, K L (1999) Some aspect of the biology of four columbid species in Zaria, Nigeria. MSc. Thesis, Department of Biological Sciences, Ahmadu Bello University, Zaria, Nigeria.

ADANG, K. L; ONIYE, S J; AJANUSI, O J; EZEALOR, A U; ABDU, P A (2008) Gastrointstinal helminth of the domestic pigeons (Columba livia domestica Gmelin, 1789 Aves: Columbidae) in Zaria, Northern Nigeria. Science World Journal 3: 33-7.

ADANG, K L; ONIYE, S J; EZEALOR, A U; ABDU, PA; AJANUSI, O J; YORIYO, K P (2009) Ectoparasites and intestinal helminths of Speckled Pigeon (Columba guinea) Hartlaub and Finsch, 1870) in Zaria, Nigeria. Science World Journal 4(2): 1-5.

AL-BARWARI, S; SAEED, I (2012) The parasitic communities of rock pigeon (Columba livia) from Iraq: component and importance. Turkiye Parazitol Derg 36: 232.

Alves, M G; Fernandes, G; Silva, T; Lopes, R; Andreatti, R (2008) Intestinal protozoan parasites with zoonotic potential in birds. Parasitol Res 103: 12371240.

BAHRAMI, A M; HOSSEINI, E; RAZMJO, R (2013) Important parasite in pigeon, its hematological parameter and pathology of intestine. World Applied Sciences Journal 21(9): 1361-1365.

BCN; DNPWC (2016) Birds of Nepal: an official checklist. Kathmandu, Nepal.

DINGLE, J; SHANAWANY, M (1999) Ostrich production system. FAO Animal Production and Health Paper 144. FAO, Rome, Italy; 256 pp (1st edition).

GHOSH, K K; ISLAM, M S; SIKDER, S; DAS, S; CHOWDHURY, S; ALIM, M A (2014). Ecto and gastrointestinal parasitic infections of pigeon at Chittagong Metropolitan area, Bangladesh. The Journal of Advances in Parasitology 1(1): 9-11.

KENNEDY, C R (1975) Ecological animal parasitology. Blackwell Scientific Publications; Oxford, London, Edinburgh, Melbourne.

Levi, W M (1969) The Pigeon. Levi Publishing, Sumter, SC, USA. 
MARQUES, S M; QUADROS, R M; DA-SILVA, C J; BALDO, M (2007) Parasites of pigeons (Columba livia) in urban areas of langes, Southern Brazil. Journal of Communicaciones Parasitol Latinoam 62: 183-187.

NAGWA, E A; EL-AKABAWY, L M; EL-MADAWY, R S; TOULAN, E I (2013) Studies on intestinal protozoa of poultry in Gharbia governorate. Benha Vet Med J 25(2):78-83.

NATALA, A J; ASEMADAHUN, N D; OKUBANJO, O O; ULAYI, B M; OWOLABI, H; JATO, I D; YUSUF, $\mathrm{K} \mathrm{H}$ (2009) A survey of parasites of domesticated pigeon (Columba livia domestic) in Zaria, Nigeria. International Journal of Soft Computing 4(4): 148-150.

OPARA, M N; OGBUEWUA, I P; IWUJIA, C T; NJOKUA, L; IHESIEA, E K; ETUKA, I F (2012) Blood characteristics, microbial and gastrointestinal parasites of street pigeons (Columba livia) in Owerri Imo State. Nigeria Scientific Journal of Animal Science 1(1): 14-21.

PATEL, P V; PATEL, A I; SAHU, R K; VYAS, R (2000) Prevalence of gastro-intestinal parasites in captive birds in Gujarat zoos. Zoos Print Journal 15(7): 295-296.

PERMIN, A; JORGEN, W H (1998). Epidemiology, diagnosis and control of poultry parasites. FAO, Rome, Italy.

RADFAR, M H; FATHI, S; ASL, E N; DEHAGHI, M M; SEGHINSARA, H R (2011) A survey of parasite of domestic pigeons (Columba livia domestica) in South Khorasan, Iran. Veterinary Research 4(1): 18-23.

RITCHIE, B W; HSARRISON, G J; ZANTOP, D; HARRISON, L R (1997) Avian medicine: principles and application. Wingers Publishing; Idaho Falls, ID, USA; pp 1007-1028.

SARI, B; KARATEPE, B; KARATEPE, M; KARA, M (2008) Parasites of domestic pigeon (Columba livia domestica) and wild pigeons (Columba livia livia) in Niğde, Turkey. Bull Vet Inst Pulawy 52: 551-554.

SIVAJOTHI, S; SUDHAKARA, R B (2015) A study on the gastro intestinal parasites of domestic pigeons in YSR Kadapa district in Andhra Pradesh, India. Journal of Dairy, Veterinary \& Animal Research 2(6): 57.

WILLIAMS, D E; CORRIGAN, R M (1994) The handbook: prevention and control of wildlife damage. University of Nebraska, Lincoln, USA; 69 pp. 


\section{ANNEX 1.}

EGGS AND CYSTS OF GASTROINTESTINAL PARASITES IN PIGEON UNDER 10X*40X ELECTRONIC MICROSCOPE.

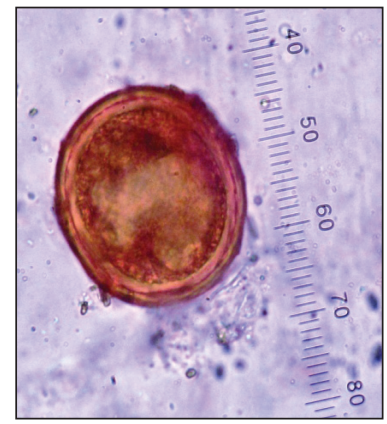

PLATE 1. Ascaridia sp. egg (75.05*56.93)

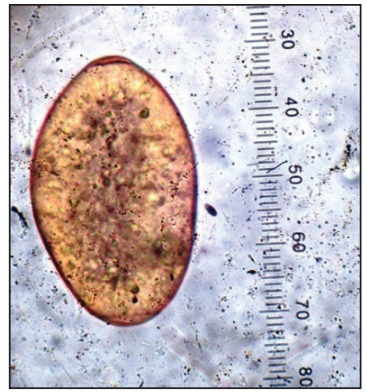

PLATE 4. Echinostoma sp. egg

(103.52*62.1)

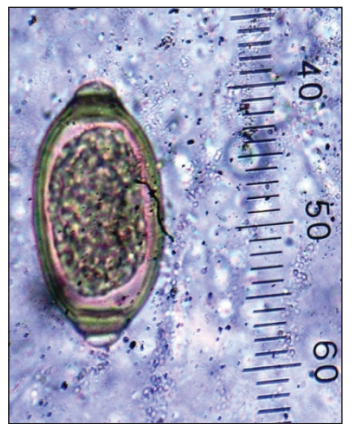

PLATE 2. Capillaria sp. egg (53.05*25.88)

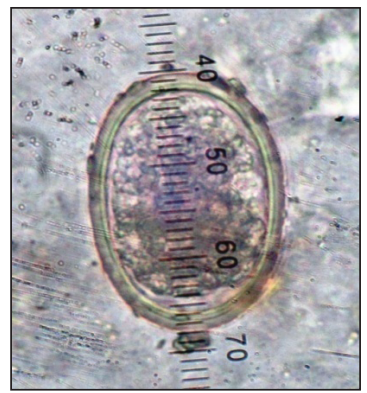

PLATE 5. Heterakis sp. egg

(46.58*72.46)

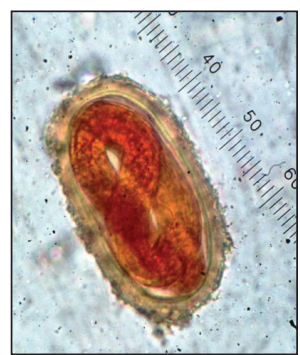

PLATE 7. Syngamus sp. Egg

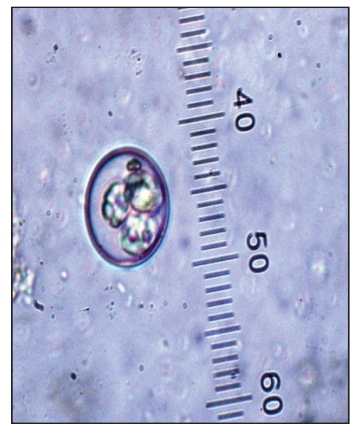

PLATE 3. Coccidia cyst (20.70 diameter)

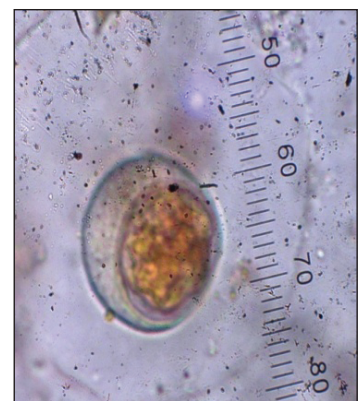

PLATE 6. Hymenolepis sp. egg (46.58 diameter) 